\title{
A NEW INTEGRATED FMEA MODEL FOR PROACTIVE HEALTHCARE RISK ANALYSIS
}

\author{
NOVI INTEGRIRANI MODEL FMEA \\ ZA PROAKTIVNU ANALIZU RIZIKA U ZDRAVSTVU
}

\author{
Xu-Qi Chen \\ School of Management, Shanghai University \\ Shanghai 200444, PR China/Kina \\ Hu-Chen Liu \\ School of Management, Shanghai University \\ Shanghai 200444, PR China/Kina \\ School of Economics and Management, Tongji University \\ Shanghai 200092, PR China/Kina \\ E-mail: huchenliu@tongji.edu.cn \\ Jian-Xin You \\ School of Economics and Management, Tongji University \\ Shanghai 200092, PR China/Kina
}

UDK/UDC: 005.334: 614.212

JEL klasifikacija/JEL classification: L15; I12

DOI: $10.30657 / \mathrm{hdmk} .2020 .24$

Izvorni znanstveni članak/Original scientific paper

Jezik/Language: Engleski/English

\begin{abstract}
This paper provides a novel risk cluster approach for healthcare failure mode and effect analysis (FMEA). Considering FMEA team members'vagueness and uncertainty in their evaluations on failure modes, picture fuzzy sets (PFSs) are advised to describe the risk evaluation result of healthcare failure modes. Moreover, clustering failure modes is more adaptable to actual needs especially under tight resources constraint. Therefore, in this paper, a new FMEA model using PFSs and k-means clustering is developed to evaluate and cluster the risk of failure modes, which is more reasonable, effective and practical for healthcare risk management.
\end{abstract}

Key words: Failure mode and effects analysis (FMEA), picture fuzzy set, $k$-means algorithm, healthcare risk analysis.

\section{INTRODUCTION}

Failure mode and effects analysis (FMEA) is a systematic risk prevention and management technique used to define, identify and eliminate potential or known failures in a system, process or service. As an effective reliability management approach, FMEA can identify the hidden hazards of a system by an established multidisciplinary team. Also, the generating 
causes and possible consequences of each failure can be obtained and evaluated so as to identify the high-risk failure modes. ${ }^{1}$ Traditionally, the risk ranking of failure modes in FMEA is achieved utilizing the risk priority number (RPN), which is derived by multiplying three risk factors namely occurrence (O), severity (S) and detection (D). Each of the three risk factors is scored using a 10-point scale. After multiplying the risk factors, the failure modes with the highest RPNs are assumed to be critical and should be focused on by proposing corrective actions. Although the conventional FMEA is an effective tool, it has some important defects in practical applications. ${ }^{2}$ First, the relative weights of risk factors are neglected in the analysis process. Second, the mathematical formula for computing RPN is unreasonable and debatable. Third, the three risk factors $\mathrm{S}, \mathrm{O}$, and $\mathrm{D}$ are difficult to be precisely evaluated because of the lack of data and the complex system to be analyzed.

In assessing the risk of failure modes, the experts are more comfortable providing their judgements in linguistic terms because they are convenient to use and consistent with people's expression habits. For depicting the linguistic information of decision makers more accurately, the concept of PFSs, proposed by Cuong and Kreinovich ${ }^{3}$ is characterized by positive membership, neutral membership and negative membership functions. It is able to deal with complex and fuzzy information, thus obtain more precise assessments of decision makers. Therefore, it is expected that the PFSs can better deal with the complex risk assessment information of experts in FMEA. In addition, a lot of efforts have been made in the past to determine the risk ranking of failure modes by using the methods. However, determining a complete ranking of failure modes is not necessary for many scenarios. Instead, it is more adaptable to cluster failure modes into priority classes especially under limited resources. ${ }^{4}$ There are a variety of clustering algorithms suggested in related articles. ${ }^{5}$ Among them, the kmeans algorithm ${ }^{6}$, because of its simplicity and robustness, is the most popular partitioningbased clustering algorithm. Against the above background, we aim to develop a new risk analysis model based on PFSs and the $k$-means algorithm to evaluate and cluster the risk of healthcare failure modes. To sum up, the main contributions of this study are summarized as follows: First, The PFSs are employed to evaluate the risk of healthcare failure modes, which can express the complicated linguistic information of FMEA experts more accurately. Second, an improved $k$-means algorithm is proposed and used to cluster healthcare failure modes into

\footnotetext{
${ }^{1} \mathrm{Hu}-\mathrm{Chen}$ Liu, "FMEA using uncertainty theories and MCDM methods," in FMEA using uncertainty theories and MCDM methods: Springer, 2016.

2 Antonella Certa, Mario Enea, Giacomo M. Galante and Concetta Manuela La Fata, "ELECTRE TRI-based approach to the failure modes classification on the basis of risk parameters: An alternative to the risk priority number," Computers and Industrial Engineering, Vol. 108, 2017. Z. P. Tian, J. Q. Wang, and H. Y. Zhang, "An integrated approach for failure mode and effects analysis based on fuzzy best-worst, relative entropy, and VIKOR methods," Applied Soft Computing Journal, Vol. 72, 2018.; Hu-Chen Liu, J. X. You, S. Chen and Y. Z. Chen, "An integrated failure mode and effect analysis approach for accurate risk assessment under uncertainty," IIE Transactions, Vol. 48, No. 11, 2016.; Z. P. Tian, J. Q. Wang, and H. Y. Zhang, “An integrated approach for failure mode and effects analysis based on fuzzy best-worst, relative entropy, and VIKOR methods," Applied Soft Computing Journal, Vol. 72, 2018.

${ }^{3}$ Bui Cong Cuong, Vladik Kreinovich, "Picture fuzzy sets - A new concept for computational intelligence problems," in 2013 3rd World Congress on Information and Communication Technologies, WICT 2013, 2014.

${ }^{4}$ Hengjie Zhang, Yucheng Dong, Ivan Palomares-Carrascosa and Haiwei Zhou, "Failure mode and effect analysis in a linguistic context: A consensus-based multiattribute group decision-making approach," IEEE Transactions on Reliability, Vol. 68, No. 2, 2019.

5 Brendan J. Frey and Nebojša Jojic, "Transformation-invariant clustering using the EM algorithm," IEEE Transactions on Pattern Analysis, Vol. 25, No. 1, 2003; Mahesh Kumar, K. and Rama Mohan Reddy, A. "A fast DBSCAN clustering algorithm by accelerating neighbor searching using Groups method," Pattern Recognition, Vol. 58, 2016.; I. O. A Odeh, A. B. McBratney and David J Chittleborough, "Soil pattern recognition with fuzzyc-means: application to classification and soil-landform interrelationships," Soil Science Society of America Journal, Vol. 56, No. 2, 1992.

${ }^{6}$ Anil Kumar Jain, "Data clustering: 50 years beyond K-means,” Pattern Recognition Letters, Vol. 31, No. 8, 2010.
} 
different risk groups. Third, a maximizing deviation method is utilized to derive the weights of risk factors. Additionally, a practical healthcare risk analysis case is provided to show the applicability and superiority of the proposed FMEA approach.

\section{PRELIMINARIES}

Definition $\mathbf{1}^{7}$. Let $X$ be a nonempty set, a PFS $A$ in $X$ can be defined as:

$$
A=\left\{\left\langle x_{i}, \mu_{A}\left(x_{i}\right), \eta_{A}\left(x_{i}\right), v_{A}\left(x_{i}\right)\right\rangle: x_{i} \in X\right\},
$$

where $\mu_{A}\left(x_{i}\right), \eta_{A}\left(x_{i}\right), v_{A}\left(x_{i}\right): X \rightarrow[0,1]$ and $\mu_{A}\left(x_{i}\right)+\eta_{A}\left(x_{i}\right)+v_{A}\left(x_{i}\right) \leq 1, \forall x_{i} \in X$. Here, $\mu_{A}\left(x_{i}\right)$ is the positive membership function of the PFSs, $\eta_{A}\left(x_{i}\right)$ is called the degree of neutral membership and $v_{A}\left(x_{i}\right)$ is the negative membership function. It is worth noting that $\xi_{A}\left(x_{i}\right)=1-\mu_{A}\left(x_{i}\right)-\eta_{A}\left(x_{i}\right)-v_{A}\left(x_{i}\right)$ is called the degree of refusal membership of the element $x_{i} \in A$. Conveniently, $\alpha=\left(\mu_{\alpha}, \eta_{\alpha}, v_{\alpha}\right)$ can be called a picture fuzzy number (PFN).

Definition $2^{8}$. Let $\alpha=\left(\mu_{\alpha}, \eta_{\alpha}, v_{\alpha}\right)$ and $\beta=\left(\mu_{\beta}, \eta_{\beta}, v_{\beta}\right)$ be two PFNs in $X$, their operational rules are given as follows:

(1) $\alpha \oplus \beta=\left(\mu_{\alpha}+\mu_{\beta}-\mu_{\alpha} \mu_{\beta}, \eta_{\alpha} \eta_{\beta}, v_{\alpha} v_{\beta}+v_{\alpha} \eta_{\beta}+v_{\beta} \eta_{\alpha}\right)$;

(2) $\alpha \otimes \beta=\left(\mu_{\alpha} \mu_{\beta}+\mu_{\alpha} \eta_{\beta}+\mu_{\beta} \eta_{\alpha}+\eta_{\alpha} \eta_{\beta}, \eta_{\alpha} \eta_{\beta}, v_{\alpha}+v_{\beta}-v_{\alpha} v_{\beta}\right)$;

(3) $\lambda \alpha=\left(1-\left(1-\mu_{\alpha}\right)^{\lambda}, \eta_{\alpha}^{\lambda},\left(v_{\alpha}+\eta_{\alpha}\right)^{\lambda}-\eta_{\alpha}^{\lambda}\right)$;

(4) $\alpha^{\lambda}=\left(\left(\mu_{\alpha}+\eta_{\alpha}\right)^{\lambda}-\eta_{\alpha}^{\lambda}, \eta_{\alpha}^{\lambda}, 1-\left(1-v_{\alpha}\right)^{\lambda}\right)$.

Definition $3^{9}$ Suppose $\alpha_{i}=\left(\mu_{\alpha_{i}}, \eta_{\alpha_{i}}, v_{\alpha_{i}}\right)(i=1,2, \ldots, n)$ be a collection of PFNs with the weight vector $w=\left(w_{1}, w_{2}, \ldots, w_{n}\right)^{T}$, where $w_{i} \in[0,1]$ and $\sum_{i=1}^{n} w_{i}=1$. Then, the picture fuzzy weighted averaging (PFWA) operator is expressed as:

$$
\begin{aligned}
& \operatorname{PFWA}\left(\alpha_{1}, \alpha_{2}, \ldots, \alpha_{n}\right)=w_{1} \alpha_{1}+w_{2} \alpha_{2}+\ldots+w_{n} \alpha_{n} \\
& =\left(1-\prod_{i=1}^{n}\left(1-\mu_{\alpha_{i}}\right)^{w_{i}}, \prod_{i=1}^{n}\left(\eta_{\alpha_{i}}\right)^{w_{i}}, \prod_{i=1}^{n}\left(v_{\alpha_{i}}+\eta_{\alpha_{i}}\right)^{w_{i}}-\prod_{i=1}^{n}\left(\eta_{\alpha_{i}}\right)^{w_{i}}\right) .
\end{aligned}
$$

\section{Definition $4^{10}$}

\footnotetext{
7 Bui Cong Cuong, Vladik Kreinovich, "Picture fuzzy sets - A new concept for computational intelligence problems," in 2013 3rd World Congress on Information and Communication Technologies, WICT 2013, 2014.

${ }^{8}$ Guiwu Wei, "Picture fuzzy aggregation operators and their application to multiple attribute decision making," Journal of Intelligent and Fuzzy Systems, Vol. 33, No. 2, 2017.

${ }^{9}$ Ibid.

${ }^{10}$ Bui Cong Cuong, Vladik Kreinovich, "Picture fuzzy sets - A new concept for computational intelligence
} 
Let $A=\left\{\left\langle x_{i}, \mu_{A}\left(x_{i}\right), \eta_{A}\left(x_{i}\right), v_{A}\left(x_{i}\right)\right\rangle: x_{i} \in X\right\}$ and $B=\left\{\left\langle x_{i}, \mu_{B}\left(x_{i}\right), \eta_{A}\left(x_{i}\right), v_{B}\left(x_{i}\right)\right\rangle: x_{i} \in X\right\}$ be two PFSs, where $i=1,2, \ldots, n$. Then, the Hamming distance between $A$ and $B$ is defined by

$$
d(A, B)=\frac{1}{n} \sum_{i=1}^{n}\left(\left|\mu_{A}\left(x_{i}\right)-\mu_{B}\left(x_{i}\right)\right|+\left|\eta_{A}\left(x_{i}\right)-\eta_{B}\left(x_{i}\right)\right|+\left|v_{A}\left(x_{i}\right)-v_{B}\left(x_{i}\right)\right|\right) .
$$

\section{THE PROPOSED FMEA MODEL}

In this section, an integrated FMEA model based on PFSs and an improved $k$-means algorithm is proposed for the risk evaluation and classification of healthcare failure modes. The flowchart of the proposed FMEA model is shown in Fig. 1.

Fig. 1 Flow diagram of the proposed FMEA model

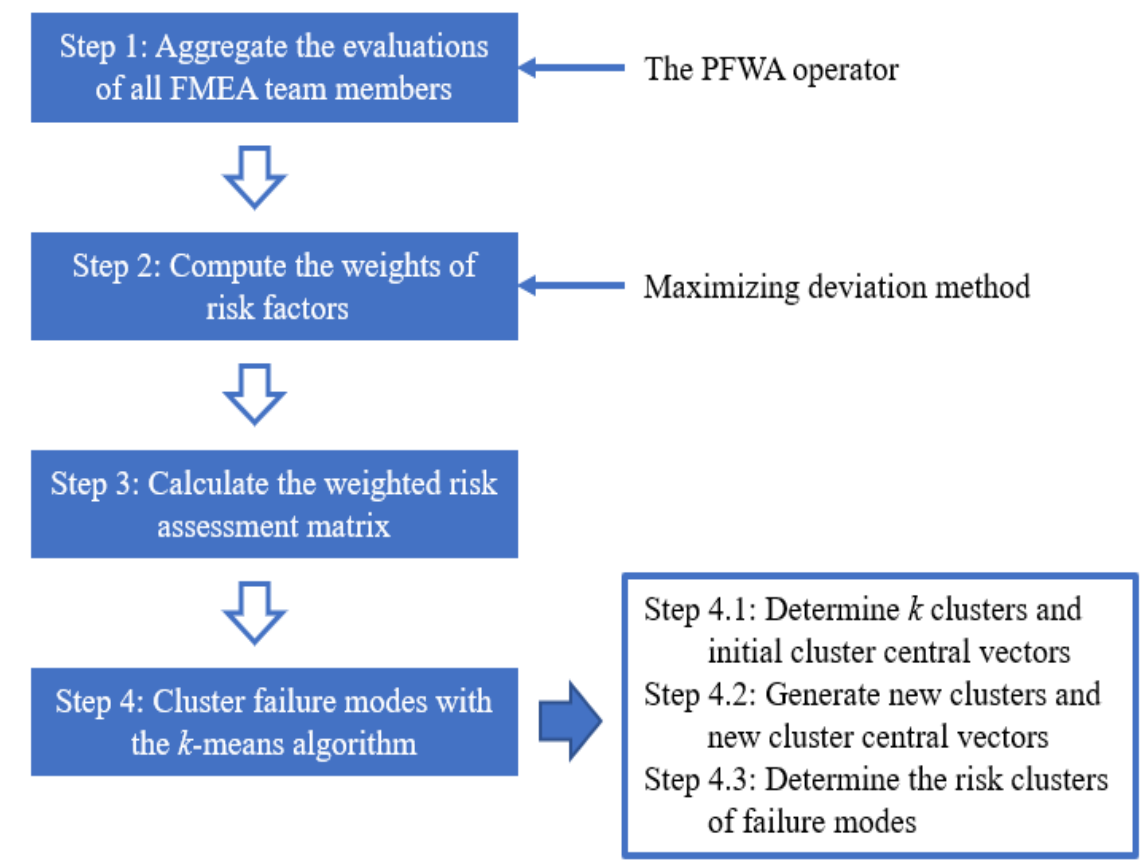

Consider a risk evaluation problem with $m$ failure modes denoted by $\mathrm{FM}_{i}$ for $i=1,2, \ldots, m$. The $m$ failure modes are evaluated with respect to $n$ risk factors $\mathrm{RF}_{j}$ for $j=1,2, \ldots, n$ by a crossfunctional FMEA team of $l$ members $\mathrm{TM}_{P}$ for $p=1,2, \ldots, l$. The weighting vector of the FMEA team members is $\lambda=\left(\lambda_{1}, \lambda_{2}, \ldots, \lambda_{l}\right)$, with $\lambda_{p}>0$ and $\sum_{p=1}^{l} \lambda_{p}=1$, revealing their different roles in the FMEA. Let $G^{p}=\left(g_{i j}^{p}\right)_{m \times n}$ be the risk assessment matrix provided by the $p$ th team member. Here, $g_{i j}^{p}=\left(\mu_{i j}^{p}, \eta_{i j}^{p}, v_{i j}^{p}\right)$ is a PFS denoting the risk evaluation of $\mathrm{FM}_{i}$ in relation to $\mathrm{RF}_{j}$.

Based on the above hypothesis and notations, the detailed steps of the proposed FMEA approach is given as follows:

Step 1: Aggregate the evaluations of all FMEA team members.

To aggregate the individual picture fuzzy evaluation matrixes

problems," in 2013 3rd World Congress on Information and Communication Technologies, WICT 2013, 2014. 
$G^{p}=\left(g_{i j}^{p}\right)_{m \times n}(p=1,2, \ldots, l)$, the PFWA operator is utilized to establish the group risk assessment matrix $G=\left(g_{i j}\right)_{m \times n}$, i.e.,

$$
P F W A\left(g_{i j}^{1}, g_{i j}^{2}, \ldots, g_{i j}^{l}\right)=\left(1-\prod_{p=1}^{l}\left(1-\mu_{i j}^{p}\right)^{\lambda_{p}}, \prod_{p=1}^{l}\left(\eta_{i j}^{p}\right)^{\lambda_{p}}, \prod_{p=1}^{l}\left(v_{i j}^{p}+\eta_{i j}^{p}\right)^{\lambda_{p}}-\prod_{p=1}^{l}\left(\eta_{i j}^{p}\right)^{\lambda_{p}}\right) \text {. }
$$

Step 2: Compute the risk factors' weights $w_{j}(j=1,2, \ldots, n)$.

Maximizing deviation is a commonly used objective weighting method for determining the weights of criteria. The risk factors' weights can be derived using the following equation

$$
w_{j}=\frac{\sum_{i=1}^{m} \sum_{y=1}^{m} d\left(g_{i j}, g_{y j}\right)}{\sum_{j=1}^{n} \sum_{i=1}^{m} \sum_{y=1}^{m} d\left(g_{i j}, g_{y j}\right)}, \text { for } j=1,2, \ldots, n,
$$

where $d\left(g_{i j}, g_{y j}\right)$, calculated via (6), represents the distance between any two failure modes with respect to each risk factor.

$$
d\left(g_{i j}, g_{y j}\right)=\frac{1}{n} \sum_{j=1}^{n}\left(\left|\mu_{i j}-\mu_{y j}\right|+\left|\eta_{i j}-\eta_{y j}\right|+\left|v_{i j}-v_{y j}\right|\right), i, y=1,2, \ldots, m, j=1,2, \ldots, n .
$$

Step 3: Calculate the weighted risk assessment matrix $G^{\prime}$.

The group risk assessment matrix $G$ acquired in Step 1 is converted into the weighted risk assessment matrix $G^{\prime}$ by

$$
\begin{aligned}
& G^{\prime}=\left(g_{i j}^{\prime}\right)_{m \times n}=w_{j}\left(g_{i j}\right)_{m \times n}=\left(1-\left(1-\mu_{i j}\right)^{w_{j}}, \eta_{i j}^{w_{j}},\left(v_{i j}+\eta_{i j}\right)^{w_{j}}-\eta_{i j}^{w_{j}}\right), \\
& \mu_{i j}^{\prime}=1-\left(1-\mu_{i j}\right)^{w_{j}}, \eta_{i j}^{\prime}=\eta_{i j}^{w_{j}}, v_{i j}^{\prime}=\left(v_{i j}+\eta_{i j}\right)^{w_{j}}-\eta_{i j}^{w_{j}} .
\end{aligned}
$$

Step 4: Cluster failure modes with the $k$-means algorithm.

The $k$-means algorithm is one of the most popular algorithms that can cluster a set of data points into a predefined number of clusters quickly. ${ }^{11}$ In the $k$-means algorithm, objects in the same cluster have great similarity, while objects in different clusters have great difference.

Step 4-1: Determine $k$ clusters and initial cluster central vectors.

In this article, an empirical method is utilized to determine the number of clusters $k$. We can select $k$ initial cluster central vectors $G_{t}^{\prime \prime}(t=1,2, \ldots, k)$ from the evaluation matrix $G^{\prime}$. First, a vector is randomly selected as the center of the first initial cluster. Second, the vector farthest from the vector is selected as the center of the second initial cluster. Third, the vector nearest to the first two vectors is selected as the center of the third initial cluster. In this way, $k$ initial cluster centers can be selected. They can be expressed as:

$$
G_{t}^{\prime \prime}=\left(g_{t 1}^{\prime \prime}, g_{t 1}^{\prime \prime}, \ldots, g_{t n}^{\prime \prime}\right), t=1,2, . ., k \text {. }
$$

Step 4-2: Generate new clusters and compute new cluster central vectors.

Based on the Hamming distance between PFSs, the distances between each failure mode $G_{i}^{\prime}$ and the $k$ initial cluster central vectors can be obtained by

$$
d\left(G_{i}^{\prime}, G_{t}^{\prime \prime}\right)=\frac{1}{n} \sum_{j=1}^{n}\left(\left|\mu_{i j}^{\prime}-\mu_{t j}^{\prime \prime}\right|+\left|\eta_{i j}^{\prime}-\eta_{t j}^{\prime \prime}\right|+\left|v_{i j}^{\prime}-v_{t j}^{\prime \prime}\right|\right), i=1,2, \ldots, m, t=1,2, \ldots, k .
$$

Then, generate new clusters of failure modes by assigning each failure mode to its

\footnotetext{
${ }^{11}$ Anil Kumar Jain, "Data clustering: 50 years beyond K-means," Pattern Recognition Letters, Vol. 31, No. 8, 2010
} 
closest cluster central vector. Calculate the mean value of each cluster and update them as new central vectors of the next iteration.

Step 4-3: Determine the risk clusters of failure modes.

Each stage of $k$-means algorithm moves every mean value to the center of the next stage and then updates by recomputing the distance from each failure mode to its nearest central vectors. Repeat Step 4-2 until the cluster results between the two iterations do not change any more. Then, this cluster is convergent, and final $k$ clusters are formed.

\section{ILLUSTRATIVE EXAMPLE}

In the section, we provide a healthcare risk analysis example about suctioning by endotracheal tube $(\mathrm{ETT})^{12}$ to justify the feasibility and effectiveness of the proposed approach for FMEA.

\subsection{Implementation}

Endotracheal suctioning is an essential nursing procedure for intubated patients from intensive care unit (ICU) ${ }^{13}$, which is performed for establishing and maintaining gas exchange, adequate oxygenation and alveolar ventilation. Normally, ETT suctioning is carried out through fourteen steps, among which a series of complications and risks will occur due to evaluation, checking or collection errors. ${ }^{14}$ Therefore, detection and prevention of these errors is extremely significant for the optimization of suctioning process and mitigating corresponding consequences, and ultimately ensuring the safety of patients. Five FMEA team members $\mathrm{TM}_{P}$ for $p=1,2,3,4,5$ from different departments were selected. The relative weights given to these five experts are $0.15,0.20,0.15,0.30$ and 0.20 in relation to their distinct domain knowledge and expertise. Ten failure modes $\mathrm{FM}_{i}$ for $i=1,2, \ldots 10$ with RPN values surpassing 350 were singled out as described in Table 1. The five team members adopt PFSs for the risk evaluation of failure modes regarding to the three risk factors $\mathrm{O}, \mathrm{S}$, and $\mathrm{D}$.

Table 1. FMEA of the endotracheal suctioning

\begin{tabular}{|l|l|l|l|l|}
\hline No. & Steps & Failure modes & Failure causes & Failure effects \\
\hline
\end{tabular}

\footnotetext{
${ }^{12}$ Agustin Vázquez-Valencia, Andrés Santiago-Sáez, Bernardo Perea-Pérez, Elena Labajo-González and Maria Elena Albarrán-Juan, "Utility of failure mode and effect analysis to improve safety in suctioning by orotracheal tube," Journal of Peri Anesthesia Nursing, Vol. 32, No. 1, 2017.

${ }^{13}$ Bülbül G. Maraş, Kocaçal E. Güler, İ. Eşer and Ş. J. I. Köse, "Knowledge and practice of intensive care nurses for endotracheal suctioning in a teaching hospital in western Turkey," Intensive Critical Care Nursing, Vol. 39, 2017.

${ }^{14}$ Agustin Vázquez-Valencia, Andrés Santiago-Sáez, Bernardo Perea-Pérez, Elena Labajo-González and Maria Elena Albarrán-Juan, "Utility of failure mode and effect analysis to improve safety in suctioning by orotracheal tube," Journal of Peri Anesthesia Nursing, Vol. 32, No. 1, 2017.
} 


\begin{tabular}{|c|c|c|c|c|}
\hline 1 & \multirow[t]{2}{*}{$\begin{array}{l}\text { Evaluating } \\
\text { need for } \\
\text { suctioning }\end{array}$} & Not evaluating & $\begin{array}{l}\text { Rushing; lack of experience; lack of } \\
\text { care; excess work load; not enough } \\
\text { personnel }\end{array}$ & $\begin{array}{l}\text { ETT obstruction; } \\
\text { excessive secretions. } \\
\text { PAMV; risk to life }\end{array}$ \\
\hline 2 & & $\begin{array}{l}\text { Inaccurate } \\
\text { evaluation }\end{array}$ & $\begin{array}{l}\text { Rushing; lack of experience; lack of } \\
\text { care; excess work load; lack of } \\
\text { knowledge; }\end{array}$ & $\begin{array}{l}\text { ETT obstruction; VAP; } \\
\text { risk to life; atelectasis }\end{array}$ \\
\hline 3 & $\begin{array}{l}\text { HD } \\
\text { evaluation }\end{array}$ & Not evaluating & $\begin{array}{l}\text { Lack of knowledge; rushing; not } \\
\text { enough personnel; lack of care; } \\
\text { oversight; habit; monitor turned off }\end{array}$ & $\begin{array}{l}\text { HD alterations; risk to } \\
\text { life }\end{array}$ \\
\hline 4 & $\begin{array}{l}\text { Informing } \\
\text { the patient }\end{array}$ & Not informing & $\begin{array}{l}\text { Patient sedated; lack of knowledge; } \\
\text { lack of care; oversight; habit }\end{array}$ & $\begin{array}{l}\text { Pain; hemodynamic } \\
\text { alterations; pulmonary } \\
\text { injuries }\end{array}$ \\
\hline 5 & \multirow{2}{*}{$\begin{array}{l}\text { Aseptic } \\
\text { technique } \\
\text { with sterile } \\
\text { gloves }\end{array}$} & $\begin{array}{l}\text { Without sterile } \\
\text { gloves }\end{array}$ & $\begin{array}{l}\text { Lack of knowledge; habit; not } \\
\text { following protocol; rushing; urgent } \\
\text { suctioning }\end{array}$ & VAP; HD alterations \\
\hline 6 & & $\begin{array}{l}\text { Improper } \\
\text { technique }\end{array}$ & $\begin{array}{l}\text { Putting gloves on wrong; not washing } \\
\text { hands; inadequate hand washing; } \\
\text { urgency }\end{array}$ & VAP; HD alterations \\
\hline 7 & \multirow[t]{4}{*}{$\begin{array}{l}\text { Introducing } \\
\text { the probe }\end{array}$} & Excessive time & $\begin{array}{l}\text { Lack of knowledge; lack of care; } \\
\text { excessive secretions; lack of } \\
\text { experience; clogged probe }\end{array}$ & $\begin{array}{l}\text { Atelectasis; HD } \\
\text { alterations; bronchial } \\
\text { spasm; risk to life }\end{array}$ \\
\hline 8 & & $\begin{array}{l}\text { Introducing probe } \\
\text { while performing } \\
\text { suctioning }\end{array}$ & $\begin{array}{l}\text { Lack of knowledge; rushing; lack of } \\
\text { experience; oversight }\end{array}$ & $\begin{array}{l}\text { Atelectasis; hypoxia; } \\
\text { HD alterations }\end{array}$ \\
\hline 9 & & $\begin{array}{l}\text { Excessive } \\
\text { suctioning }\end{array}$ & $\begin{array}{l}\text { Lack of knowledge; lack of } \\
\text { experience; bad habits }\end{array}$ & VAP; HD alterations \\
\hline 10 & & $\begin{array}{l}\text { Lack of aseptic } \\
\text { technique }\end{array}$ & $\begin{array}{l}\text { Poor technique; lack of experience; } \\
\text { reused or contaminated probe }\end{array}$ & VAP \\
\hline
\end{tabular}

The linguistic terms defined by PFNs are outlined in Table 2. Next, the proposed FMEA approach is utilized to determine the most critical failures in the ETT suctioning process, which includes the following steps:

Table 2. Linguistic term sets defined by PFNs

\begin{tabular}{|c|c|}
\hline Linguistic Term & Picture Fuzzy Number \\
\hline Very Low & $(0.10,0.00,0.85)$ \\
\hline Low & $(0.25,0.05,0.60)$ \\
\hline Medium Low & $(0.30,0.00,0.60)$ \\
\hline Medium & $(0.50,0.10,0.40)$ \\
\hline Medium High & $(0.60,0.00,0.30)$ \\
\hline High & $(0.75,0.05,0.10)$ \\
\hline Very High & $(0.90,0.00,0.05)$ \\
\hline
\end{tabular}

For example, the assessment information, represented by PFNs, of the ten failure modes given by the first FMEA team member $\mathrm{TM}_{1}$ is presented in Table 3 .

Table 3. The evaluation matrix given by $\mathrm{TM}_{1}$ 


\begin{tabular}{|l|l|l|l|}
\hline \multirow{2}{*}{$\begin{array}{c}\text { Failure } \\
\text { modes }\end{array}$} & \multicolumn{3}{c|}{ Risk factors } \\
\cline { 2 - 4 } & \multicolumn{1}{|c|}{$\mathrm{O}$} & \multicolumn{1}{c|}{$\mathrm{S}$} & \multicolumn{1}{c|}{$\mathrm{D}$} \\
\hline $\mathrm{FM}_{1}$ & $(0.6,0,0.3)$ & $(0.9,0,0.05)$ & $(0.75,0.05,0.1)$ \\
\hline $\mathrm{FM}_{2}$ & $(0.9,0,0.05)$ & $(0.9,0,0.05)$ & $(0.75,0.05,0.1)$ \\
\hline $\mathrm{FM}_{3}$ & $(0.75,0.05,0.1)$ & $(0.9,0,0.05)$ & $(0.6,0,0.3)$ \\
\hline $\mathrm{FM}_{4}$ & $(0.9,0,0.05)$ & $(0.75,0.05,0.1)$ & $(0.75,0.05,0.1)$ \\
\hline $\mathrm{FM}_{5}$ & $(0.75,0.05,0.1)$ & $(0.75,0.05,0.1)$ & $(0.75,0.05,0.1)$ \\
\hline $\mathrm{FM}_{6}$ & $(0.9,0,0.05)$ & $(0.75,0.05,0.1)$ & $(0.75,0.05,0.1)$ \\
\hline $\mathrm{FM}_{7}$ & $(0.75,0.05,0.1)$ & $(0.9,0,0.05)$ & $(0.6,0,0.3)$ \\
\hline $\mathrm{FM}_{8}$ & $(0.75,0.05,0.1)$ & $(0.75,0.05,0.1)$ & $(0.6,0,0.3)$ \\
\hline $\mathrm{FM}_{9}$ & $(0.75,0.05,0.1)$ & $(0.75,0.05,0.1)$ & $(0.75,0.05,0.1)$ \\
\hline $\mathrm{FM}_{10}$ & $(0.75,0.05,0.1)$ & $(0.75,0.05,0.1)$ & $(0.75,0.05,0.1)$ \\
\hline
\end{tabular}

Step 1: The linguistic risk assessment matrixes $G^{p}=\left(g_{i j}^{p}\right)_{10 \times 3}(p=1,2,3,4,5)$ are aggregated using (4) to acquire the group risk evaluation matrix $G=\left(g_{i j}\right)_{10 \times 3}$ as shown in Table 4.

Table 4. Aggregated risk assessments on the ten failure modes

\begin{tabular}{|l|l|l|l|}
\hline \multirow{2}{*}{$\begin{array}{c}\text { Failure } \\
\text { modes }\end{array}$} & \multicolumn{3}{|c|}{ Risk factors } \\
\cline { 2 - 4 } & \multicolumn{1}{|c|}{$\mathrm{O}$} & \multicolumn{1}{c|}{$\mathrm{S}$} \\
\hline $\mathrm{FM}_{1}$ & $(0.66,0,0.24)$ & $(0.88,0,0.06)$ & $(0.73,0,0.17)$ \\
\hline $\mathrm{FM}_{2}$ & $(0.84,0,0.09)$ & $(0.82,0,0.1)$ & $(0.84,0,0.09)$ \\
\hline $\mathrm{FM}_{3}$ & $(0.73,0,0.17)$ & $(0.88,0,0.06)$ & $(0.64,0,0.26)$ \\
\hline $\mathrm{FM}_{4}$ & $(0.78,0,0.14)$ & $(0.68,0,0.21)$ & $(0.75,0.05,0.1)$ \\
\hline $\mathrm{FM}_{5}$ & $(0.75,0.05,0.1)$ & $(0.73,0,0.17)$ & $(0.76,0,0.15)$ \\
\hline $\mathrm{FM}_{6}$ & $(0.88,0,0.06)$ & $(0.79,0,0.12)$ & $(0.78,0,0.14)$ \\
\hline $\mathrm{FM}_{7}$ & $(0.73,0,0.17)$ & $(0.9,0,0.05)$ & $(0.6,0,0.3)$ \\
\hline $\mathrm{FM}_{8}$ & $(0.71,0,0.19)$ & $(0.75,0.05,0.1)$ & $(0.65,0,0.24)$ \\
\hline $\mathrm{FM}_{9}$ & $(0.84,0,0.09)$ & $(0.71,0,0.19)$ & $(0.73,0,0.17)$ \\
\hline $\mathrm{FM}_{10}$ & $(0.75,0.05,0.1)$ & $(0.68,0,0.21)$ & $(0.71,0,0.19)$ \\
\hline
\end{tabular}

Step 2: After calculating the distances between all the failure modes in terms of each risk factor, The three risk factors' weights are derived as $w_{1}=0.314, w_{2}=0.352$ and $w_{3}=0.334$ by (5)-(6).

Step 3: Obtain the weighted risk evaluation matrix $G^{\prime}=\left(g_{i j}^{\prime}\right)_{10 \times 3}$ via (7) as shown in Table 5.

Step 4: This step is to cluster failure modes with the $k$-means algorithm.

First, three initial cluster central vectors are selected as follows:

$$
\begin{aligned}
& G_{1}^{\prime \prime}=[(0.35,0.39,0.16),(0.37,0.00,0.53),(0.38,0.00,0.53)], \\
& G_{2}^{\prime \prime}=[(0.49,0.00,0.42),(0.42,0.00,0.47),(0.39,0.00,0.51)], \\
& G_{3}^{\prime \prime}=[(0.44,0.00,0.46),(0.35,0.00,0.56),(0.35,0.00,0.56)] .
\end{aligned}
$$

Based on (9), the distances between each failure mode and the three initial cluster central vectors can be calculated. Besides, new clusters and new central vectors are generated. 
Table 5. Weighted risk evaluation matrix

\begin{tabular}{|l|l|l|l|}
\hline \multirow{2}{*}{$\begin{array}{c}\text { Failure } \\
\text { mode }\end{array}$} & \multicolumn{3}{|c|}{ Risk factor } \\
\cline { 2 - 4 } & \multicolumn{1}{|c|}{$\mathrm{O}$} & \multicolumn{1}{c|}{$\mathrm{S}$} \\
\hline $\mathrm{FM}_{1}$ & $(0.29,0,0.63)$ & $(0.53,0,0.38)$ & $(0.35,0,0.56)$ \\
\hline $\mathrm{FM}_{2}$ & $(0.44,0,0.46)$ & $(0.45,0,0.45)$ & $(0.45,0,0.45)$ \\
\hline $\mathrm{FM}_{3}$ & $(0.33,0,0.58)$ & $(0.53,0,0.38)$ & $(0.29,0,0.64)$ \\
\hline $\mathrm{FM}_{4}$ & $(0.37,0,0.54)$ & $(0.33,0,0.58)$ & $(0.37,0.37,0.16)$ \\
\hline $\mathrm{FM}_{5}$ & $(0.35,0.39,0.16)$ & $(0.37,0,0.53)$ & $(0.38,0,0.53)$ \\
\hline $\mathrm{FM}_{6}$ & $(0.49,0,0.42)$ & $(0.42,0,0.47)$ & $(0.39,0,0.51)$ \\
\hline $\mathrm{FM}_{7}$ & $(0.33,0,0.58)$ & $(0.56,0,0.35)$ & $(0.26,0,0.67)$ \\
\hline $\mathrm{FM}_{8}$ & $(0.32,0,0.59)$ & $(0.39,0.35,0.16)$ & $(0.30,0,0.62)$ \\
\hline $\mathrm{FM}_{9}$ & $(0.44,0,0.46)$ & $(0.35,0,0.56)$ & $(0.35,0,0.56)$ \\
\hline $\mathrm{FM}_{10}$ & $(0.35,0.39,0.16)$ & $(0.33,0,0.58)$ & $(0.34,0,0.58)$ \\
\hline
\end{tabular}

After two iterations, the clusters are stabilized and convergent. The three risk clusters of failure modes are presented in Fig.2, and the specific cluster results are given in Table 6.

Table 6. Results of clusters

\begin{tabular}{|l|l|}
\hline \multicolumn{1}{|c|}{ Cluster } & \multicolumn{1}{c|}{ Failure mode } \\
\hline High-risk cluster & $\mathrm{FM}_{2}, \mathrm{FM}_{6}$ \\
\hline Medium-risk cluster & $\mathrm{FM}_{1}, \mathrm{FM}_{3}, \mathrm{FM}_{4}, \mathrm{FM}_{7}, \mathrm{FM}_{8}, \mathrm{FM}_{9}$ \\
\hline Low-risk cluster & $\mathrm{FM}_{5}, \mathrm{FM}_{10}$ \\
\hline
\end{tabular}

Fig. 2 Results of clusters

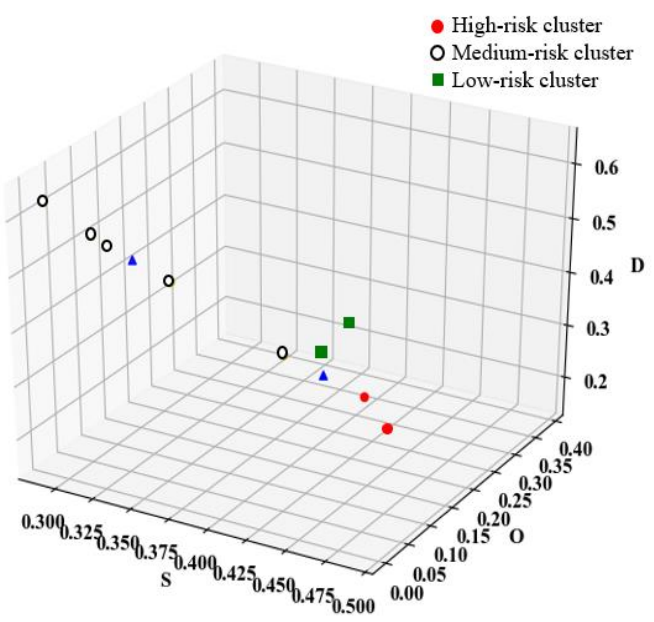

\subsection{Comparisons and discussions}

To account for the effectiveness of the proposed FMEA, a comparison with the traditional RPN method and the fuzzy TOPSIS ${ }^{15}$ is presented. Table 7 exhibits the rankings of

\footnotetext{
${ }^{15}$ Ahmet Can Kutlu and Mehmet Ekmekçioğlu, "Fuzzy failure modes and effects analysis by using fuzzy TOPSISbased fuzzy AHP," Expert Systems with Applications, Vol. 39, No. 1, 2012.
} 
the 10 failure modes by the two methods and the risk cluster result by the proposed FMEA.

Table 7. Ranking comparisons

\begin{tabular}{|l|r|r|r|r|r|r|c|}
\hline \multirow{2}{*}{ Failure modes } & \multicolumn{9}{|c|}{ Traditional FMEA } & \multicolumn{1}{c|}{ Fuzzy TOPSIS } & Proposed model \\
\cline { 2 - 8 } & O & \multicolumn{1}{|c|}{ S } & D & \multicolumn{1}{c|}{ RPN } & \multicolumn{1}{c|}{ Ranking } & Ranking & Risk clusters \\
\hline $\mathrm{FM}_{1}$ & 6 & 9 & 8 & 432 & 4 & 9 & $\mathrm{M}$ \\
\hline $\mathrm{FM}_{2}$ & 9 & 9 & 8 & 648 & 1 & 1 & $\mathrm{H}$ \\
\hline $\mathrm{FM}_{3}$ & 8 & 9 & 6 & 432 & 4 & 8 & $\mathrm{M}$ \\
\hline $\mathrm{FM}_{4}$ & 8 & 8 & 8 & 512 & 3 & 5 & $\mathrm{M}$ \\
\hline $\mathrm{FM}_{5}$ & 8 & 8 & 8 & 512 & 3 & 6 & $\mathrm{~L}$ \\
\hline $\mathrm{FM}_{6}$ & 9 & 8 & 8 & 576 & 2 & 3 & $\mathrm{H}$ \\
\hline $\mathrm{FM}_{7}$ & 8 & 9 & 6 & 432 & 4 & 7 & $\mathrm{M}$ \\
\hline $\mathrm{FM}_{8}$ & 8 & 8 & 6 & 384 & 5 & 10 & $\mathrm{M}$ \\
\hline $\mathrm{FM}_{9}$ & 8 & 8 & 8 & 512 & 3 & 2 & $\mathrm{M}$ \\
\hline $\mathrm{FM}_{10}$ & 8 & 8 & 8 & 512 & 3 & 4 & $\mathrm{~L}$ \\
\hline
\end{tabular}

On the one hand, the proposed FMEA model show some inconsistent results with the traditional RPN method. As obtained in Table 7, the failure modes prioritize three are $\mathrm{FM}_{4}=$ $\mathrm{FM}_{5}=\mathrm{FM}_{9}=\mathrm{FM}_{10}$. However, $\mathrm{FM}_{5}$ and $\mathrm{FM}_{10}$ are not medium-risk failure mode in the proposed FMEA method despite its same RPN value is the same with $\mathrm{FM}_{4}$ and FM9. Thus, the traditional RPN method could not differentiate the failure modes that have the same RPN value but different risk factor combinations. The proposed FMEA model can solve this defect to make the results more accurate and precise.

On the other hand, the proposed FMEA method is weakly consistent with the fuzzy TOPSIS method. For example, the risk ranking of the bottom two failure modes by the fuzzy TOPSIS method is $\mathrm{FM}_{8}$ and $\mathrm{FM}_{1}$. However, in the proposed FMEA model, $\mathrm{FM}_{8}$ and $\mathrm{FM}_{1}$ are not the low-risk failure modes. Two reasons may lead to the ranking differences between the two methods. First, the fuzzy TOPSIS method is incapable of handling complex and fuzzy evaluating assessments, which leads to the loss of the initial information. Second, the fuzzy TOPSIS method determines the risk ranking of failure modes based on the TOPSIS algorithm, whereas the proposed FMEA clusters failure modes by a clustering analysis method.

The comparison analyses made above have manifested the effectiveness of the proposed risk priority approach in improving the performance of FMEA. Compared with the listed methods, the benefits of the proposed FMEA are summed up as follows:

- It allows experts to evaluate failure modes by PFSs, which is characterized by positive membership, neutral membership and negative membership functions. It is able to deal with complex and fuzzy information, thus obtain more precise assessments of decision makers.

- Via the maximizing deviation method, the risk factor weights are taken into consideration for visualizing the influential degree of different combinations of $\mathrm{O}$, $\mathrm{S}$ and $\mathrm{D}$, which makes the proposed approach more practical and reasonable.

- An improved $k$-means algorithm is utilized to cluster the failure modes into priority classes. Hence, the high-risk failure modes can be identified efficiently by the proposed model. This is more adaptable to actual needs, especially under tight resource constraints.

\section{CONCLUSION}

In this article, we proposed a new FMEA model by integrating PFSs and an improved $k$-means algorithm to evaluate and cluster the risk of healthcare failure modes. By using PFSs, 
the risk evaluation information of FMEA team members could be represented more accurately. The improved $k$-means algorithm could cluster healthcare failure modes into high-, medium-, and low-risk groups. Additionally, a maximizing deviation approach is utilized to calculate the risk factor weights. Finally, a risk assessment case of the ETT suctioning process was presented to validate the proposed FMEA model. A comparative analysis was further carried out to illustrate the effectiveness of the proposed FMEA. The results showed that the new risk clustering model for FMEA was more reasonable, effective, and practical for risk management and reliability analysis.

\title{
Sažetak:
}

\author{
NOVI INTEGRIRANI MODEL FMEA \\ ZA PROAKTIVNU ANALIZU RIZIKA U ZDRAVSTVU
}

Ovaj rad donosi novi pristup grupi rizika za analizu načina rada i učinka neuspjeha u zdravstvu (FMEA). Uzimajući u obzir nejasnoće $i$ nesigurnost članova tima FMEA-e u njihovim procjenama načina neuspjeha, savjetuje se primjena slikovnih nejasnih setova (PFS-ovi) u svrhu opisa rezultata procjene rizika zbog načina neuspjeha u zdravstvu. Nadalje, načini neuspjeha u grupi prilagodljiviji su stvarnim potrebama, posebno pod strogim ograničenjem resursa. Stoga je u ovom radu razvijen novi model FMEA koji koristi PFS i k-znači grupiranje, kako bi se procijenio i grupirao rizik od neuspjeha, koji je razumniji, učinkovitiji i praktičniji za upravljanje rizikom zdravstvene zaštite.

Key words: Failure mode and effects analysis (FMEA), slikovni nejasni setovi, k-znači algoritam, analiza rizika $u$ zdravstvu.

\section{LITERATURE}

1. Certa, Antonella, Enea, M., Galante, G. M., and Manuela C. La Fata, "ELECTRE TRIbased approach to the failure modes classification on the basis of risk parameters: An alternative to the risk priority number," Computers and Industrial Engineering, Vol. 108, 2017.

2. Cuong, B. C. and V. Kreinovich, "Picture fuzzy sets - A new concept for computational intelligence problems," in 2013 3rd World Congress on Information and Communication Technologies, WICT 2013, 2014.

3. Frey, B. J. and N. Jojic, "Transformation-invariant clustering using the EM algorithm," IEEE Transactions on Pattern Analysis, Vol. 25, No. 1, 2003.

4. Jain, A. K., "Data clustering: 50 years beyond K-means," Pattern Recognition Letters, Vol. 31, No. 8, 2010.

5. Kutlu, A. C. and M. Ekmekçioğlu, "Fuzzy failure modes and effects analysis by using fuzzy TOPSIS-based fuzzy AHP,” Expert Systems with Applications, Vol. 39, No. 1, 2012.

6. Liu, H. C., "FMEA using uncertainty theories and MCDM methods," in FMEA using uncertainty theories and MCDM methods: Springer, 2016.

7. Liu, H. C., You, J. X., Chen, S., and Y. Z. Chen, "An integrated failure mode and effect analysis approach for accurate risk assessment under uncertainty," IIE Transactions, Vol. 48, No. 11, 2016.

8. Mahesh Kumar, K. and A. Rama Mohan Reddy, "A fast DBSCAN clustering algorithm by accelerating neighbor searching using Groups method," Pattern Recognition, Vol. 58, 2016.

9. Maraş, G. B., Güler, E. K., Eşer, İ. and Ş. J. I. Köse, "Knowledge and practice of intensive care nurses for endotracheal suctioning in a teaching hospital in western Turkey," Intensive Critical Care Nursing, Vol. 39, 2017. 
10. Odeh, I. O. A., McBratney, A. B., and D. J. Chittleborough, "Soil pattern recognition with fuzzy-c-means: application to classification and soil-landform interrelationships," Soil Science Society of America Journal, Vol. 56, No. 2, 1992.

11. Tian, Z. P., Wang, J. Q., and H. Y. Zhang, "An integrated approach for failure mode and effects analysis based on fuzzy best-worst, relative entropy, and VIKOR methods," Applied Soft Computing Journal, Vol. 72, 2018.

12. Vázquez-Valencia, A., Santiago-Sáez, A., Perea-Pérez, B., Labajo-González, Elena, and Maria Elena Albarrán-Juan, "Utility of failure mode and effect analysis to improve safety in suctioning by orotracheal tube," Journal of PeriAnesthesia Nursing, Vol. 32, No. 1, 2017.

13. Wei, G. "Picture fuzzy aggregation operators and their application to multiple attribute decision making," Journal of Intelligent and Fuzzy Systems, Vol. 33, No. 2, 2017.

14. Zhang, H., Dong, Y., Palomares-Carrascosa, I. and H. Zhou, "Failure mode and effect analysis in a linguistic context: A consensus-based multiattribute group decision-making approach,” IEEE Transactions on Reliability, Vol. 68, No. 2, 2019. 